\title{
Knowledge Management Processes for B-Schools
}

\author{
Anil K S, Shubha Muralidhar
}

\begin{abstract}
This study, explores the intentions of institutions of Indian B-Schools academicians towards knowledge management and knowledge management processes. The use of knowledge management is recognized as an institutional capacity and tends towards growth. A review is conducted based on knowledge management treated as strategic and tactical plan. A pilot study is carried out and the findings are presented in the paper. The pilot study is based on the responses to the questionnaire prepared on the basis of literature. A closer link has to be brought in between the knowledge management and knowledge management processes as it helps our future managers and also provide them the skills they require throughout their life. It is felt that there should be a stronger requirement for change and responses from universities to address them and close the gap. There could be the knowledge management and its practices contributing to the performance of B-Schools and overall development of the institution.
\end{abstract}

Keywords : Knowledge, Knowledge Management, Knowledge Management processes and B-Schools.

\section{INTRODUCTION}

A vast literature has identified the gap between knowledge management and its processes in higher education and also brings about the awareness and its importance. Attempts have been made continuously to bridge this gap. The size and causes of the gap between knowledge management and its processes are based on emphasis amongst B-Schools. The gap is more prominent in B-Schools, there is a link between knowledge management and knowledge management processes. For knowledge management and knowledge management processes there is a wider agenda. The focus is on bridging the gap between knowledge management and knowledge management processes. It is confirmed that strengthening of knowledge management and knowledge management processes has lot of potential in delivering the skills required by the upcoming generation of administrators. Several questions require responses one is interested to know the factors raised by faculty that has impact on knowledge management. The cause for the gap along with remedies must be addressed by the universities. The intention of the academicians is for knowledge management or knowledge management processes to be explored which could trigger their preferences. [6]

Revised Manuscript Received on July 25, 2019

Anil K S, Shubha Muralidhar, Research Scholar, BMSCE, Dept of MBA Bangalore, Assistant Professor, BMS College of Engineering, Dept. Of MBA, Bangalore

\section{LITERATURE REVIEW}

\section{WHAT IS KNOWLEDGE?}

Basically the meaning of knowledge and the most accepted one is it is true, justified and a belief [2]. It can be said to be a clear perception of the action and a factual knowledge. The knowledge interpretations derived through the researchers are illustrated with examples in the Table 1

\section{Source: Reference [2]}

The overview of the definitions of knowledge can be categorized and figured out as

1. There is clear distinction between data and information.

2. It could be in the minds or expressive.

3. It can be organizational as well as personal

Knowledge can be said on the basis of a function as a process to get the information, share it, interpret and share into facts that are intellectual and can be used by single or in groups. Based on the classifications, the knowledge can be classified into innovation, core and advanced. Core knowledge is the minimum time and knowledge level required for the game to be played. Knowledge level doesn't give and ensure a viable term which is long. The knowledge is held by members of the industry and which in turn provides a little advantage over the non-members, the advanced knowledge is completely viable. The knowledge is of same level and quality though the knowledge content may vary from the competitors. Thus the organizations prefer to get head on with people in same positions hoping to know more than the competitor. Innovative knowledge allows the organization to take the lead of the industry and the competitors by showing that they significantly differentiate it from the competitors. This infers to say that the organization familiarity and an orientation link between the knowledge and strategy seem to be unique and different and may reflect advantage. The relation between knowledge and strategy is distinct and could show advantage. Thus the strategic knowledge which comprises of these three knowledge forms the construct origin of organisational advantage.

\section{WHAT IS KNOWLEDGE MANAGEMENT?}

This is defined from several aspects by the researchers and scholars where knowledge is managed systematically to search, create, share, organize, facilitate and evaluate the various aspects in using the technology and making decisions. Knowledge management can be considered as a process to evaluate, capture, discover, apply, create, store and filter from the individuals to accomplish 


\section{Knowledge Management Processes for B-Schools}

the organization goals and objectives as told by Karadsheh et. al (2009). Drucker feels as long as there are persons working in an organization with knowledge will constitute knowledge management. The various definitions of Knowledge Management with typical examples are listed in Table 2.

Table 1: Various concepts of knowledge [2]

\begin{tabular}{|c|c|c|}
\hline No. & Author(s) and date & Definition \\
\hline 1 & Darling, 1996 & $\begin{array}{l}\text { Intangible assets of the organization, such as the social basis of the state and includes } \\
\text { extensive experience and excellent management style and culture accumulated. }\end{array}$ \\
\hline 2 & $\begin{array}{l}\text { O’Dell and Grayson, } \\
1998\end{array}$ & Define knowledge to be information in action. \\
\hline 3 & $\begin{array}{l}\text { Davenport and Prusak, } \\
1998\end{array}$ & $\begin{array}{l}\text { A fluid mix of framed experience, values, contextual information, and expert insight that } \\
\text { provides a framework for evaluating and incorporating new experiences and information. It } \\
\text { originates and is applied in the minds of experts. In organizations, it often becomes } \\
\text { embedded not only in documents or repositories but also in organizational routines, } \\
\text { processes, practices, and norms". }\end{array}$ \\
\hline 4 & Beijerse, 1999 & $\begin{array}{l}\text { The capability to interpret data and information through a process of giving meaning to these } \\
\text { data and information; and an attitude aimed at wanting to do so. }\end{array}$ \\
\hline 5 & $\begin{array}{l}\text { Stromquista and Samoff, } \\
2000\end{array}$ & $\begin{array}{l}\text { The Knowledge is systematic experiments and test for the hypotheses that refer to objective } \\
\text { and explanatory model for understanding the surroundings environment. }\end{array}$ \\
\hline 6 & Smith, 2001 & $\begin{array}{l}\text { A human, highly personal asset representing the shared expertise and efforts of networks } \\
\text { and alliances. }\end{array}$ \\
\hline 7 & Nonaka et al., 2001 & Define knowledge that it is explicit knowledge and tacit knowledge. \\
\hline 8 & Wiig, 2004 & $\begin{array}{l}\text { Facts, perspectives and concepts, mental reference models, truths and beliefs, judgments } \\
\text { and expectations, methodologies, and know-how. Understanding how to create new } \\
\text { meanings out of isolated information. }\end{array}$ \\
\hline 9 & Awad and Ghaziri, 2004 & $\begin{array}{l}\text { Higher level of abstraction that resides in people's minds. Includes perception, skills, training, } \\
\text { common sense, and experiences. }\end{array}$ \\
\hline 10 & Desouza, 2005 & Placement of information in its larger context a necessary condition for understanding. \\
\hline 11 & Yeh, 2005 & $\begin{array}{l}\text { Knowledge refers to the ideas or understandings that an entity creates and/or possesses that } \\
\text { are used to take effective action to achieve the entity's goals. }\end{array}$ \\
\hline 12 & Leng, 2005 & $\begin{array}{l}\text { Sees that knowledge has two basic definitions of interest. First, Knowledge is defined as } \\
\text { structure of information such as facts, opinions, ideas, theories, principles, models (or other } \\
\text { framework). Second, Knowledge is also defined as person's stage of being for instant, } \\
\text { ignorance, awareness, familiarity, competencies, intuitions, understanding, facility and etc. }\end{array}$ \\
\hline 13 & Laihonen, 2006 & Regarded knowledge as containing an interpretation of a knower. \\
\hline 14 & Williams, 2006 & Characterized knowledge as is dynamic, strategic, political, and subject to change. \\
\hline 15 & $\begin{array}{l}\text { Laudon and Laudon, } \\
2006\end{array}$ & $\begin{array}{l}\text { Define knowledge assets as organizational knowledge regarding how to efficiently and } \\
\text { effectively perform business processes and create new products and services that enables } \\
\text { the business to create value. }\end{array}$ \\
\hline 16 & Endres et al. 2007 & $\begin{array}{l}\text { Define knowledge from an organizational point of view. Organization is considered a valuable } \\
\text { resource and potential source of capabilities and competencies for innovations and new } \\
\text { product development, it is consists of information, technology, know-how, and skills. Value } \\
\text { and sustainability are created from the integration of these resources better than competitors. }\end{array}$ \\
\hline 17 & Gao et al. 2008 & Knowledge can be further defined as subjective or objective; or explicit or tacit/implicit. \\
\hline 18 & Vandaie, 2008 & From the epistemological perspective, knowledge is known to be either tacit or explicit. \\
\hline
\end{tabular}


19 Seidler and Hartmann, 2008

20 Faucher et al. 2008

21 Karadsheh et al. 2009

22 Al-Zayyat et al. 2009
Knowledge is a potentially significant resource to the firm as it may possess valuable, rare, inimitable and non-substitutable characteristics particularly if it has a tacit dimension.

Knowledge is considered to be information that has been processed in some meaningful ways.

Knowledge is the result of merging information with practice, perspective and expression, resulting in insinuation and presents approaches and plans on which decision is based on.

State two concepts for the knowledge: first as an economic resource; second as a source of competitive advantage making significant impact on the traditional management approach and demanded a model change. This in turn created an wealth of intellectual capital, human capital, structural capital, knowledge capital, customer capital, human intellectual assets, intangible assets, knowledge worker, and competent employee, all emphasizing the utilization of a rare and special kind of human resource.

Table 2: Definitions of knowledge management [2]

\begin{tabular}{lll}
\hline KM definition & Description & Reference \\
& $\begin{array}{l}\text { The process of collecting, organizing, classifying and disseminating information throughout an } \\
\text { organization, so as to make it purposeful to those who need it. }\end{array}$ & Albert, 1998 \\
&
\end{tabular}

Defines knowledge management is a process that facilitates knowledge sharing and

Singh, 2008 establishes learning as continuous process within an organization.

KM Processes knowledge, and process from knowledge which leads to improve the internal and external operation

Knowledge management is a group of clearly defined processes or methods used to search important knowledge among different knowledge management operations.

Knowledge management is a systematic approach to managing organizational knowledge and activities include creating, structuring, organizing, retrieving, sharing, and evaluating an enternrise's knowledge assets.

Knowledge management is the strategic application of collective company knowledge and know-how to build profits and market share. Knowledge assets-both ideas or concepts and know-how-are created through the computerized collection, storage, sharing, and linking of

$\mathrm{KM}$ as a strategic perspective corporate knowledge pools. Advanced technologies make it possible to mine the corporate mind.

$(\mathrm{KM})$ is not really about managing knowledge, but rather managing and creating a corporate culture that facilitates and encourages the sharing, appropriate utilization, and creation of knowledge that enables a corporate strategic competitive advantage.

$\mathrm{KM}$ as a It is organized and systemic process for acquiring, organizing and exchanging knowledge among employees in order to effectively utilizing knowledge.

technical perspective

$\mathrm{KM}$ as a perspective of value-added

Knowledge management is the new contemporary technological application of knowledge in critical planning, appraisal, decision making, evaluation and redesign of operative systems.

It is processes and practices through which organizations generate value from knowledge offers valuable tools for creating, developing, maintaining, and replicating organizational capabilities.

Knowledge management as an entity's systematic and deliberate efforts to expand, cultivates, and applies available knowledge in ways that add value to the entity; in the sense of positive results in accomplishing its objectives or fulfilling its purpose.

Knowledge management can be idea of as a deliberate design of processes, tools, structures, with the intent to increase, renew, share or improve the use of knowledge represented in any of the three elements (structural, human, and social) of intellectual capital.

$\mathrm{KM}$ as an intangible asset

Knowledge management is the practice of harnessing and exploiting intellectual capital in order to gain competitive advantage and customer commitment through efficiency, innovation and effective decision-makina.

It is a process of producing knowledge to transport the organization into learning organization. Parikh, 2001

KM Learning
Alryalat and AL-Hawari, 2008

Liu et al., 2005, 637

Kim et al., 2008

Zuckerman \& Buell, 1998

Walczak, 2005

Alavi and Leidner, 2001

Kibet et al. 2010

Grant, 2009

Holsapple, 2004

Seeman et al. 1999

Yeh, 2005

(KM) based on knowledge management Learning as a structure based on past experience

Miltiadis et al. and build new mechanisms for exchanging and generating new knowledge.

2002

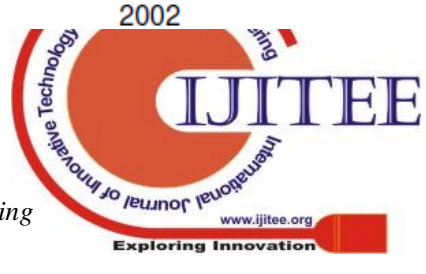




\begin{abstract}
Innovation
process

$\mathrm{KM}$ as a process which contains creation, acquisition, incorporation, allocation, and application of knowledge to advance the operation efficiency and competitive advantage of an organization. Knowledge management presents the right information to the right group at the right time.

Albers and

Brewer, 2003
\end{abstract}

Knowledge

architecture

(CRM)

Adoption
It is a methodical means of administrating this valuable resource, by promoting an incorporated approach to identifying, capturing, structuring, organizing, retrieving, sharing, and evaluating an enterprise's knowledge assets.

$\mathrm{KM}$ as a methodical leveraging of data, information, proficiency and different structures of assets and resources to enhance organizational innovation, reaction, efficiency and capability.
Kim et al. 2004

Goh, 2005
Source: Reference [2]

Life cycle activities grow and declines depending based on competence available in the organization. The various areas of knowledge could be classified as:

1. The components of knowledge in infancy stage which shows that there is capacity to alter execution of many tasks in the institution.

2. The important areas of knowledge classify the institution from other units and have maximum effect on the distinct position in the institution

3. The fundamental areas of knowledge carry out the activities of the organization and in every institution it is almost identical in nature

4. Areas not used in practice are rarely being used for business. Knowledge management is implemented in various stages until it matures.

With the knowledge available in the institution one can obtain the promising knowledge. In stimulation of core knowledge, knowledge management can realize and identify the knowledge required during business operations. To distribute the basic knowledge and refresh the outdated knowledge, Knowledge Management can provide the easy access required and update the knowledge to be stored to maintain the Knowledge Management. The Knowledge life cycle is shown in Figure 1.

\begin{tabular}{|c|c|c|}
\hline 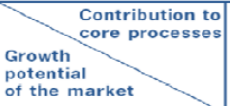 & High contribution & Low contribution \\
\hline $\begin{array}{l}\text { High } \\
\text { growth }\end{array}$ & $\begin{array}{l}\text { Key } \\
\text { knowledge } \\
\text { areas }\end{array}$ & $\begin{array}{l}\text { Promising } \\
\text { knowledge } \\
\text { areas }\end{array}$ \\
\hline $\begin{array}{l}\text { Low } \\
\text { growth }\end{array}$ & $\begin{array}{l}\text { Basic } \\
\text { knowledge } \\
\text { areas }\end{array}$ & $\begin{array}{l}\text { Outdated } \\
\text { knowledge } \\
\text { areas }\end{array}$ \\
\hline
\end{tabular}

Figure 1: The Knowledge life cycle Source: Reference [2] [2]

Anil and Shubha Muralidhar [10] illustrates the need and benefits of knowledge management in B-Schools. Anil and Shubha Muralidhar [11] have also touched on

Entrepreneurship education in B-schools.

\section{NATURE OF KNOWLEDGE MANAGEMENT AND ITS PROCESSES}

As per resource-based view, the resources are personnel based; tangible and intangible happen to be the fundamental units of analyses that create the capabilities of the organizations by working together. Capabilities here refer to be able to integrate use and apply valuable inputs which add on to the knowledge management. The capability of knowledge management can be categorized along three dimensions, namely knowledge processes, knowledge skills and knowledge infrastructures. The knowledge generation processes include works where new knowledge is evolved.
The consolidation of knowledge is gained by transfer of knowledge. Improving the knowledge is done through the available knowledge. In addition to application the measurement of the process takes place that justify and measure the value of business knowledge.

Change in the institutional knowledge is the first sign of knowledge management. They are said to be dual in nature as one side there is the knowledge manipulation process which involves the acquiring of knowledge, convert into useful form, apply the knowledge and protect the knowledge. On the other side, it identifies that both culture and issues of organization play an important role in the deployment of knowledge management systems. The second dimension is knowledge skills, the knowledge management by nature are multi-faceted which involve dimensions human, organizational and technical. Chief Knowledge Officer should be a planner, evaluator and a human resource person. The person is able to facilitate the process of sharing the knowledge and the renewal of knowledge which facilitates the sharing of the information and is able to utilize the technologies available. With the ability to serve the creation of knowledge, sharing and document the knowledge are some of the required skills. The last being the infrastructure which has its technical side having more of information technology related activities like collaboration, discovering knowledge, mapping of knowledge and distributed learning. The structural side refers to the structure of the organization, its system of rewards and incentives. The cultural side has the vision and the organizations system values. [1]

\section{OBJECTIVES}

The primary objective of the study is to explore the intentions of academicians of Indian B-Schools. The next one being is to conduct a qualitative study on Indian B-Schools academicians, processes the data collected and draw conclusion from the study.

\section{METHODOLOGY}

This study is an exploratory one where questionnaire is framed based on various studies from the literature survey. The questions are designed by dividing into three parts as A, $\mathrm{B}$ and $\mathrm{C}$ where part $\mathrm{A}$ is the demographic information, part $\mathrm{B}$ is based on the Knowledge Management practices which are the independent variables and the competitive advantage which is the dependent variable. The practices considered here are five of them with questions framed under each practice and also under competitive advantage. Part $\mathrm{C}$ had questions which involved in listing or ticking more than one option. All the questions in part B were framed based on a 5-point Likert scale with

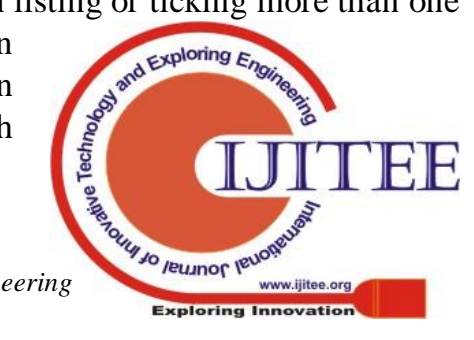


value for each of them like 5 means strongly agree to 1 means strongly disagree. The questions are presented in a printed form as a hard copy so that they can fill and give back the same. The responses were collected from 42 respondents while the distribution was done to around 60 respondents. The questions were distributed to 5 colleges in South Bengaluru responses are collected in person from the respondents.

The dimensions of the quantitatively collected responses are reduced using Exploratory Factor Analysis (EFA). Promax oblique rotation was used to clearly classify a total of 42 variables into factors with least cross-loading variables among them.

\section{RESULTS AND INFERENCES}

The methodology is described in detail considering the reliability and validity parameters which is used for the full data. Reliability is determined using SPSS (25.0) using Cronbach's alpha values. It was found to be greater than 0.9 meaning the scales are highly reliable. The results have been shown in Table 3. The closer the Cronbach's value to 1.00, the more reliable the instrument is. Since the measured value is greater than 0.75 , the items in the questionnaire are acceptable (Mertens, 2014). [27]

Table 3: Reliability Statistics

\begin{tabular}{|r|r|}
\hline $\begin{array}{c}\text { Cronbach's } \\
\text { Alpha }\end{array}$ & N of Items \\
\hline .959 & 62 \\
\hline
\end{tabular}

As a general purpose, the mean, standard deviation and variance of every item is determined and shown in Table 4

Table 4: Descriptive Statistics

\begin{tabular}{|l|c|c|c|c|c|c|}
\hline & & Mini & Maxi & & $\begin{array}{c}\text { Std. } \\
\text { Deviati } \\
\text { on }\end{array}$ & Variance \\
\hline Knowledge & & mum & mum & Mean & & \\
Acquisition & 43 & 2.82 & 5.00 & 3.8689 & .55166 & .304 \\
Knowledge & & & & & & \\
Documentati & 43 & 1.43 & 5.00 & 3.5150 & .78565 & .617 \\
on & & & & & & .281 \\
KS & 43 & 1.89 & 4.00 & 3.0388 & .53004 & .482 \\
KC & 43 & 1.71 & 5.00 & 3.5581 & .69415 & .655 \\
KAP & 43 & 1.67 & 5.00 & 3.5465 & .80944 & \\
Valid N & 43 & & & & & \\
(listwise) & & & & & \\
\hline
\end{tabular}

The Kaiser-Meyer-Olkin (KMO) test was performed under exploratory factor analysis and the values so determined reflected the variance proportion because of the underlying factors. The KMO value having a number near to 1 show that factor analysis is useful. The number has to be at least 0.50 for the factor analysis usefulness, as a rule of thumb. Even though the sample size is 42 the KMO value,
0.519 is more than the expected cut-off value of 0.50 which means to say that factor analysis proves to be of use with value being thrice the number of variables i.e., 3 x $42=126$. In performing the Bartlett's test the p-value obtained is less than the minimum threshold significance of 0.05 thus we reject the null hypothesis as the correlation matrix being an identity matrix and the factor analysis is useful data as shown in Table 5.

Table 5: KMO and Bartlett's Test

\begin{tabular}{|c|c|c|}
\hline \multicolumn{2}{|c|}{ Kaiser-Meyer-Olkin Measure of Sampling Adequacy. } & .519 \\
\hline \multirow[t]{3}{*}{ Bartlett's Test of Sphericity } & Approx. Chi-Square & 1455.725 \\
\hline & df & 741 \\
\hline & Sig. & .000 \\
\hline
\end{tabular}

As per our study, the significance value i.e., 0.000 happens to be far less than required value. Thus the factor analysis is useful in the study.

As per the null hypothesis, assuming there is no difference seen among the items because of which the initial communalities as shown in Table 6 are all equal, i.e., 1.000. under principal component analysis after running exploratory factor analysis the values are not found to be the same. Thus the null hypothesis is rejected and inferred that proportion of variance and the other variables are not equal. The extraction communalities contribute to the estimates of variance of each variable that are accounted by the factors which also support our decision to reject null hypothesis. The values are large enough to be accounted for in our case.

Table 6: Communalities

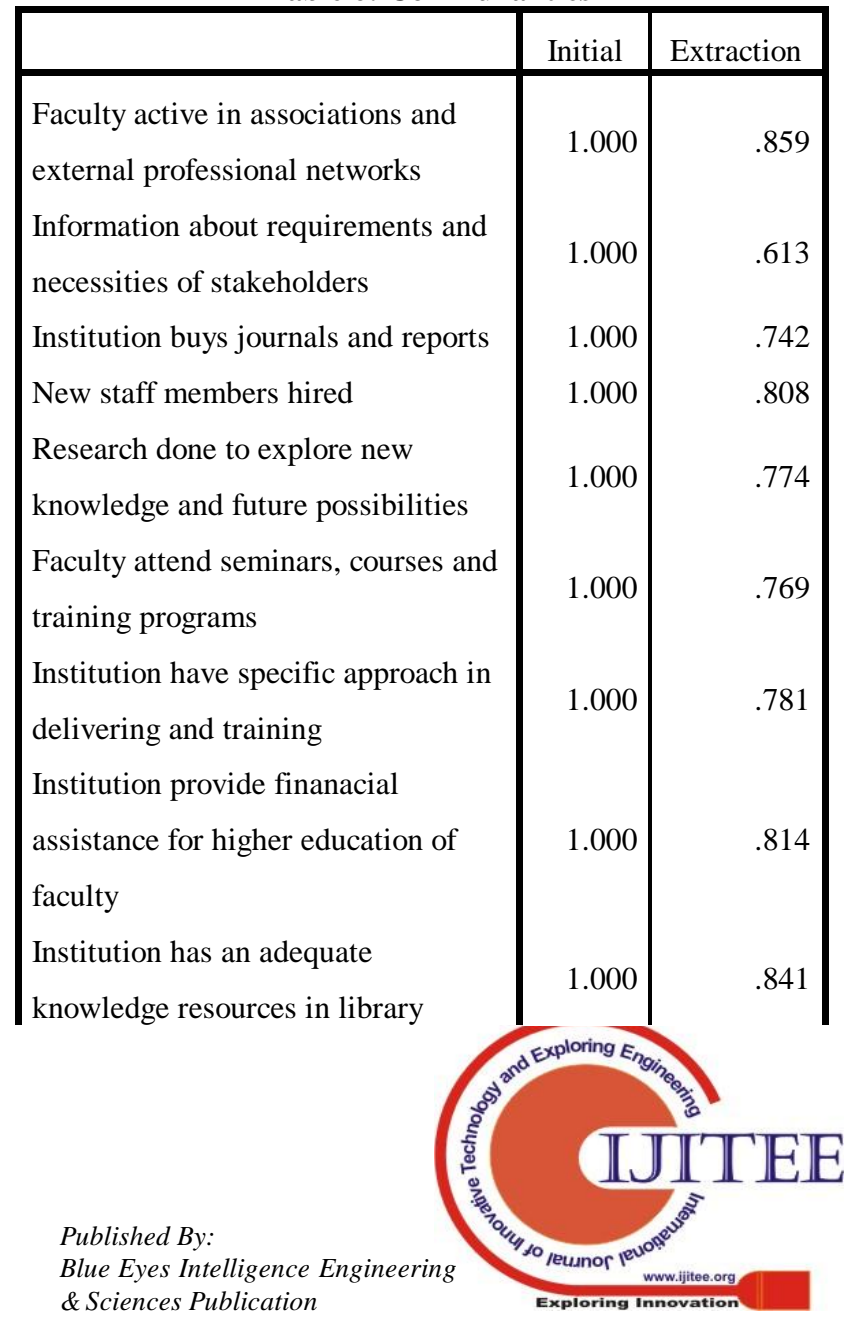


Knowledge Management Processes for B-Schools

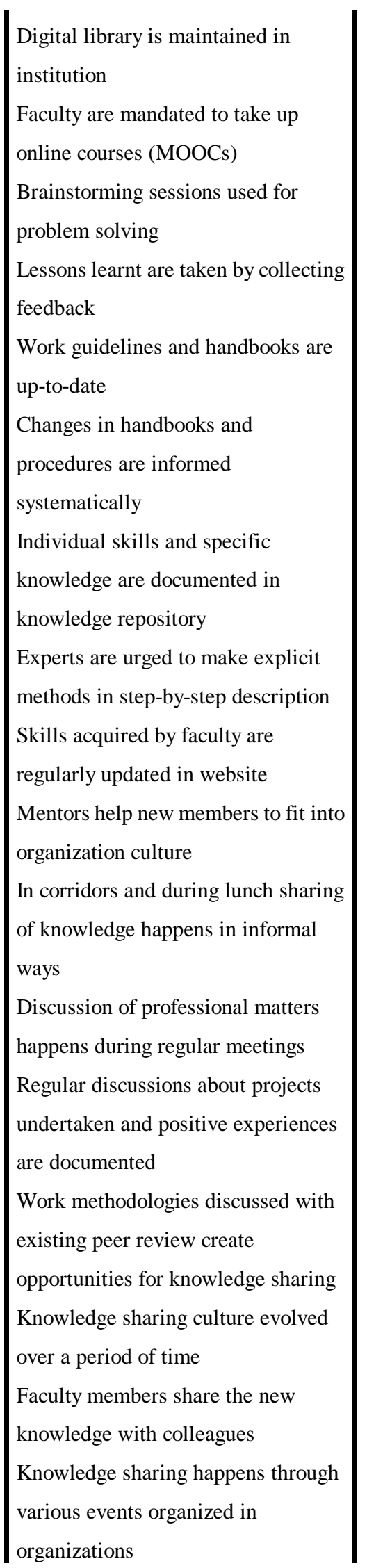

\begin{tabular}{|c|c|}
\hline 1.000 & .850 \\
\hline 1.000 & .718 \\
\hline 1.000 & .826 \\
\hline 1.000 & .798 \\
\hline 1.000 & .859 \\
\hline 1.000 & .881 \\
\hline 1.000 & .761 \\
\hline 1.000 & .798 \\
\hline 1.000 & .789 \\
\hline 1.000 & .709 \\
\hline 1.000 & .725 \\
\hline 1.000 & .828 \\
\hline 1.000 & .795 \\
\hline 1.000 & .832 \\
\hline 1.000 & .825 \\
\hline 1.000 & .740 \\
\hline 1.000 & .713 \\
\hline
\end{tabular}

Value addition of faculty and organization by attending conferences and seminars are assessed

Doubts, failures and problems are discussed openly

Documented knowledge shared on website viz. minutes of meeting Assigning new projects done based on availability

For testing new ideas and developing new knowledge members are

rewarded

Discussion of strategies and work experiences through

research/innovation cell are discussed

Involvement of alumini with organization brings culture of creating new knowledge Through consultancies selling of knowledge attracts explicit attention Improvisation of courses and programs are done utilizing experiences of students and stakeholders

In institution one makes use of of existing faculty and alumni

knowledge in a creative manner Knowledge in repository is promoted internally by faculty in institution

Multi-disciplinary projects carried out in th institution

Stakeholders are approached before developing new course or program 
International Journal of Innovative Technology and Exploring Engineering (IJITEE) ISSN: 2278-3075, Volume-8 Issue-9S3, July 2019

Table 7: Total Variance Explained

\begin{tabular}{|c|c|c|c|c|c|c|c|c|c|}
\hline \multirow[b]{2}{*}{ SI No } & \multicolumn{3}{|c|}{ Initial Eigenvalues } & \multicolumn{3}{|c|}{$\begin{array}{l}\text { Extraction Sums of Squared } \\
\text { Loadings }\end{array}$} & \multicolumn{3}{|c|}{ Rotation Sums of Squared Loadings } \\
\hline & Total & $\begin{array}{c}\% \text { of } \\
\text { Variance }\end{array}$ & $\begin{array}{c}\text { Cumulativ } \\
\text { e \% }\end{array}$ & Total & $\begin{array}{c}\% \text { of } \\
\text { Variance }\end{array}$ & $\begin{array}{l}\text { Cumulativ } \\
\text { e } \%\end{array}$ & Total & $\begin{array}{l}\% \text { of } \\
\text { Variance }\end{array}$ & $\begin{array}{l}\text { Cumulativ } \\
\text { e } \%\end{array}$ \\
\hline 1 & 13.832 & 35.467 & 35.467 & 13.832 & 35.467 & 35.467 & 7.811 & 20.028 & 20.028 \\
\hline 2 & 3.419 & 8.766 & 44.234 & 3.419 & 8.766 & 44.234 & 5.68 & 14.565 & 34.593 \\
\hline 3 & 2.366 & 6.067 & 50.301 & 2.366 & 6.067 & 50.301 & 4.489 & 11.509 & 46.102 \\
\hline 4 & 2.149 & 5.511 & 55.812 & 2.149 & 5.511 & 55.812 & 3.368 & 8.636 & 54.738 \\
\hline 5 & 1.749 & 4.484 & 60.296 & 1.749 & 4.484 & 60.296 & 2.168 & 5.558 & 60.296 \\
\hline 6 & 1.684 & 4.317 & 64.613 & & & & & & \\
\hline 7 & 1.528 & 3.918 & 68.53 & & & & & & \\
\hline 8 & 1.371 & 3.515 & 72.046 & & & & & & \\
\hline 9 & 1.144 & 2.933 & 74.978 & & & & & & \\
\hline 10 & 1.089 & 2.791 & 77.769 & & & & & & \\
\hline 11 & 0.947 & 2.427 & 80.197 & & & & & & \\
\hline 12 & 0.9 & 2.309 & 82.506 & & & & & & \\
\hline 13 & 0.83 & 2.128 & 84.634 & & & & & & \\
\hline 14 & 0.77 & 1.975 & 86.609 & & & & & & \\
\hline 15 & 0.615 & 1.576 & 88.185 & & & & & & \\
\hline 16 & 0.572 & 1.467 & 89.653 & & & & & & \\
\hline 17 & 0.538 & 1.379 & 91.031 & & & & & & \\
\hline 18 & 0.519 & 1.332 & 92.363 & & & & & & \\
\hline 19 & 0.478 & 1.226 & 93.589 & & & & & & \\
\hline 20 & 0.386 & 0.991 & 94.58 & & & & & & \\
\hline 21 & 0.377 & 0.966 & 95.546 & & & & & & \\
\hline 22 & 0.291 & 0.745 & 96.291 & & & & & & \\
\hline 23 & 0.243 & 0.623 & 96.914 & & & & & & \\
\hline 24 & 0.226 & 0.579 & 97.493 & & & & & & \\
\hline 25 & 0.192 & 0.491 & 97.984 & & & & & & \\
\hline 26 & 0.155 & 0.397 & 98.381 & & & & & & \\
\hline 27 & 0.132 & 0.337 & 98.718 & & & & & & \\
\hline 28 & 0.118 & 0.302 & 99.02 & & & & & & \\
\hline 29 & 0.091 & 0.232 & 99.253 & & & & & & \\
\hline 30 & 0.078 & 0.2 & 99.453 & & & & & & \\
\hline 31 & 0.053 & 0.135 & 99.588 & & & & & & \\
\hline 32 & 0.045 & 0.116 & 99.704 & & & & & & \\
\hline 33 & 0.039 & 0.099 & 99.803 & & & & & & \\
\hline 34 & 0.029 & 0.075 & 99.878 & & & & & & \\
\hline 35 & 0.018 & 0.046 & 99.923 & & & & & & \\
\hline 36 & 0.011 & 0.028 & 99.951 & & & & & & \\
\hline 37 & 0.01 & 0.025 & 99.977 & & & & & & \\
\hline 38 & 0.006 & 0.014 & 99.991 & & & & & & \\
\hline 39 & 0.003 & 0.009 & 100 & & & & & & \\
\hline
\end{tabular}

Extraction Method: Principal Component Analysis.

In concern with the number of factors turned out to be six after rotation as shown in Table 5. The value accounts for little more than $65 \%$ (cut off for acceptance) of the variability in the original values. This means to say that six latent influences are connected with knowledge management and knowledge management processes but still there is a lot of variation to be 
explained i.e. $64.613-55.812=9$ (approx.).

The scree plot shown in Figure 2 confirms the factors selected. Thus there is a need for rotation being felt and was attained through promax rotation technique.

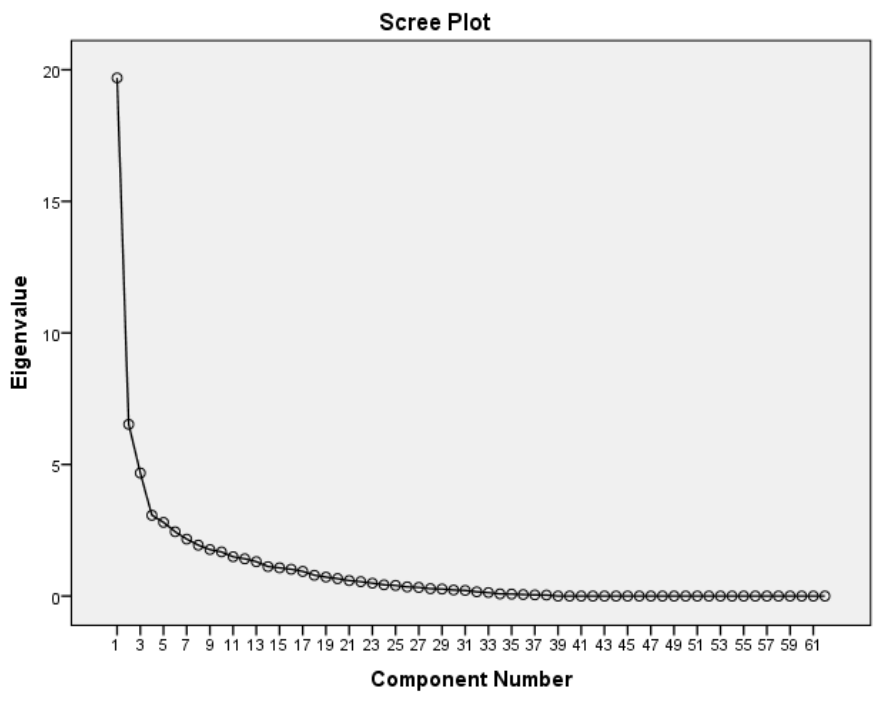

Figure 2: Scree Plot

\section{Conclusion}

Integration of knowledge management and its processes can build the student findings by also providing the tools required in understanding both. In doing so a stage is set for students so as to incorporate the management principles that are based on evidence into ones who are the decision making professionals. A closer link has to be brought in between the two as it helps our future managers and also provide them the skills they require throughout their life.

In the present scenario and the previous experiences put together the integration of knowledge management and its processes do not take place naturally. There are found to be several elements like work force, characteristics at individual and institutional level, cultures of profession and society which all act as barriers to have an easy exchange of knowledge management and its processes. It is felt that there should be a stronger requirement for change and responses from universities to address them and close the gap. To overcome or reduce the gap it is essential that one understands the factors to close the gap. To attain balance between knowledge management and knowledge management processes the concepts has to be seen individually.

Both complement each other is what the faculty also should know. Institutions can always take feedback and try to revise and implement in the policy which brings in a conducive atmosphere. It might be happening in some and may not in some other but measures have to be taken to reduce or close the gap. For this the faculty has to identify those factors that are affecting the choice of faculty. In doing so the institutions can build the policies, give the required support which brings in a harmony between knowledge management and its processes. It is essential that these two are given equal weightage amongst B-Schools. This is all possible if the future managers understand its value and act in accordance realizing its need.

The contribution to the prevailing study is about applying knowledge management and its practices by academicians of Indian B-Schools. A good ground work can be taken up so as to continue on the quantitative studies and further study their relationships. A model can be proposed based on the determinants that are obtained based on the performance of the individuals and their contributions to the institutions as a whole. If a micro level study on these determinants are continued then the top management may focus on these areas. Thus there could be the knowledge management and its practices contributing to the performance of B-School and overall development of the institution.

Further findings from the study help the university in designing new interventions to enhance knowledge management and its practices. The model proposed which connects the determinants and the performance of B-School can be tested empirically. In doing so it gives clarity about the academician's role which extensively contributes to the performance of the institution. Once this is realized, B-schools can come out with new strategies to promote knowledge management and its practices accordingly.

\section{REFERENCES}

[1] Zeid and Ekionea (2005), "Knowledge Management and Sustained Competitive Advantage: A Resource-Based Analysis", Idea Group Publishing, pp. 622-625, Managing Modern Organizations With Information Technology, 2005, URL-http://www.idea-group.com

[2] Mahdi et al. (2011), "The role of knowledge and knowledge management in sustaining competitive advantage within organizations: A review", African Journal of Business Management ,Vol. 5(23), pp. 9912-9931, http://www.academicjournals.org/AJBM DOI: 10.5897/AJBM11.1118 ISSN 1993-8233 @2011 Academic Journals.

[3] Albert S (1998). Knowledge Management: Living Up To The Hype?. Midrange Syst., 11(13): 52.

[4] Singh SK (2008). Role of leadership in knowledge management: a study. J. Knowl. Manage. 12(4): 3-15.

[5] Alryalat H, AL-Hawari S (2008). A review of Theoretical Framework: How to Make Process about, for, from Knowledge work. 9th International Business Information Management Association Conference, pp. 37-50.

[6] Liu PL, Chen WC, Tsai CH (2005). An Empirical Study on Correlation between the Knowledge Management Method and New Product Development Strategy on Product Performance in Taiwan's Industries. Technovation, 25: 637-644.

[7] Kim SK, Lim S, Mitchell RB (2008). A Method for Knowledge Modeling with unified modeling Language (UML): Building a Blueprint for Knowledge Management. In M. E. Jennex (Eds.) Current Issues in Knowledge Management. New York.

[8] Zuckerman A, Buell H (1998). Is the world ready for knowledge management?. Qual. Progr., 31(6): 81-84.

[9] Walczak S (2005). Organizational knowledge management structure. Learn. Organ. 12(4): 330-339.

[10] Alavi M, Leidner D (2001). Knowledge management and knowledge management systems: Conceptual foundations and research issues. Manage. Inform. Syst. Q., 25(1): 107-136.

[11] Kibet KS, Samuel CK, Magutu PO, Richard NB (2010). Knowledge Management as Source Of Sustainable Competitive Advantage Comparative Assessment of Egerton University Farms and Private Commercial Farms. Afr. J. Bus. Manage. (AJBUMA), 1: 70-83.

[12] Grant RM (1996). Toward a knowledge-based view of the firm. Strateg. Manage. J. 17: 109-122.

[13] Holsapple CW, Joshi KD (2004). A Formal Knowledge Management Ontology: Conduct, Activities, Resources, and Influences. J. Am. Soc. Inform. Sci. Technol. 55(7): 593-612. 
[14] Seeman P, DeLong D, Stucky S, Guthrie E (1999). Building Intangible Assets: A Strategic Framework for Investing in Intellectual Capital. Second International Conference on the Practical Applications Knowledge Manage. (PAKeM99).

[15] Yeh YMC (2005). The Implementation of Knowledge Management System in Taiwan's Higher Education. J. Coll. Teach. Learn., 2(9): 35-42.

[16] Parikh M (2001). Knowledge Management Framework for High tech Research and Development. Engineering Manage. J. 13(3): 27-34.

[17] Miltiadis L, Pouloudi A, Poulymenakou A (2002). Knowledge management convergence expanding learning frontiers. J. Knowl Manage. 6(1): 40-51.

[18] Albers JA, Brewer S (2003). Knowledge Management and the Innovation Process: The Eco Innovation Model. J. Knowl. Manage. Pract., 4: 1-10.

[19] Kim K, Lim S, Mitchell B (2004). Building A Knowledge Model: A Decision-Making Approach. J. Knowl. Manage. Pract., 5(4): 300-310.

[20] Goh ALS (2005). Adoption of Customer Relationship Management (CRM) Solutions as an Effective Knowledge Management (KM) Tool: A Systems Value Diagnostic. J. Knowl. Manage. Pract., 4(2): 153-158.

[21] Chikati and Mpofu (2013), "Developing Sustainable Competitive Advantage Through Knowledge Management", International Journal Of Scientific \& Technology Research Volume 2, Issue 10, OCTOBER 2013 ISSN $2277-8616$ pp. 77-81, IJSTR@2013 www.ijstr.org .

[22] Halawi L, Aronson J and McCarthy R (2005) "Resource-Based View of Knowledge Management for Competitive Advantage" The Electronic Journal of Knowledge Management Volume 3 Issue 2, pp 75-86, available online at www.ejkm.com, ISSN 1479-4411.

[23] Sharafuddin (2017), "The Role Of Knowledge Management In Achieving Sustainable Competitive Advantage In Business" , pp. 137-142, Journal of Education and Social Sciences, Vol. 6, Issue 2, (February) ISSN 2289-1552.

[24] Shaheen et al. (2013), "Behavioral Intentions of Academicians Towards Teaching and Research: A Study in the Indian B-School Context", The IUP Journal of Soft Skills, Vol. VIII, No. 3, 2014, pp. 8-31.

[25] Anil and Shubha Muralidhar (2018), "Need and Benefits of Knowledge Management in B-Schools", Shanlax International Journal of Management, pp.85-89, Vol.5, Special Issue 4 April 2018, ISSN 2321 4643.

[26] Anil and Shubha Muralidhar (2018), "Entrepreneurship Education in Business Schools", International Journal of Exclusive Management Research, pp.1-6, Special Issue April 2018, IJEMR, www.ijemr.in , ISSN $2249-2585$.

[27] Mertens, D. M. (2014). Research and Evaluation in Education and Psychology: Integrating Diversity With Quantitative, Qualitative, and Mixed Methods: Integrating Diversity With Quantitative, Qualitative, and Mixed Methods. UK: Sage Publications.

[28] Anil and Shubha Muralidhar (2018a), "Need and Benefits of Knowledge Management in B-Schools", Shanlax International Journal of Management, pp.85-89, Vol.5, Special Issue 4 April 2018, ISSN 2321 4643.

[29] Anil and Shubha Muralidhar (2018b), "Entrepreneurship Education in Business Schools", International Journal of Exclusive Management Research, pp.1-6, Special Issue April 2018, IJEMR, www.ijemr.in , ISSN $2249-2585$ 